\title{
O Arranjo Produtivo Local como Potencializador da Vantagem Competitiva: A VISÃO DOS PARTICIPANTESDO APL DE TURISMO Região LagOASEM AlagOAS
}

\author{
VictorSouza Sgarbi \\ MestreemAdministraçãopda \\ UniversidadeFedeal dePernamburo \\ vidarsganbi@gmail.com
}

\section{RESUMO}

Este trabalho compreende questões sobre os aspectos motivadores para 0 aumento da competitividade das empresas participantes de um Arranjo Produtivo Local de serviços, na perspectiva dos que fazem parte do APL de Turismo Região Lagoas. É apresentada uma revisão do conceito de competitividade e de APL, incluindo o Modelo de Competitividade Sistêmica do GDI e o modelo de evolução dos APLs de Machado (2003). O levantamento de dados foi realizado, prioritariamente, por meio de entrevistas semiestruturadas. Tal levantamento mostrou que as principais características que contribuem para a competitividade das empresas participantes deste APL são o aumento da capacitação da mão-de-obra da região, a cooperação entre os participantes e um destaque para 0 aumento da divulgação da região, normalmente não referenciado na bibliografia sobre 0 assunto.

Palavras-chave: Arranjo Produtivo Local. Competitividade. Evolução dos APLs. Competitividade Sistêmica. Instituto Alemão de D esenvolvimento.

\section{ABSTRACT}

This studyindudes questions about themotivating aspets of the increin thecompetitiveness of companies partiapatingin a Local ProductiveArrangement (LPA) of services from thevieupoint of thosewhotakepart in theLagoons Rejon's TourismLPA. It presents a review of theconept of compeitivenessandLPA, induding theGeman Dexdqument Institute's Modd of Systeric Competitiveness, andMachadb'smodd of LPA evdution(2003). Thesurvey was conducted primarily through semi-structured interviens It showed that themain features that contributeto the competitiveness of the companies partiapatingin thisLPA indudean incresein theworkforcecapaity in theregion, coperation between theparticipants, and a speial attention totheincrein the adketising of theregion, nomally not referened in the literature on the subjet.

Keywords: Loal ProdudiveArrangement. Competitiveness LPA Evdution SystemicCompetitiveness Geman Dexdqpment Institute 


\section{INTRODUÇÃo}

A criação de um mercado aberto internacional, proporcionado pela globalização, apresenta diversas mudanças no seu contexto. A constante busca das empresas por obter uma vantagem competitiva sustentável foi dificultada após a entrada de concorrentes mundiais nos mercados internos de vários países.

Pequenas empresas, não preparadas para competir neste mercado estão entrando em decadência ou buscando formas de continuar competitivas. A formação de redes mostra-se bastante eficiente neste quesito. Algumas propostas alternativas de crescimento das PMEs consideram a criação de redes de empresas. Estas redes de cooperação estão se espalhando pelo mundo e no Brasil ganhou maior força com a criação, pelo Governo Federal, do Grupo de Trabalho Permanente (GTP-APL), com o intuito de integrar ações governamentais, e de outras agências, para estimular esses arranjos produtivos (NO RO NHA; TURCHI, 2005).

As redes sociais contribuem com empresas e produtores ao minimizar as dificuldades individuais e, ao mesmo tempo, maximizar os seus pontos positivos. A difusão da lógica de redes modifica a operação e os resultados dos processos produtivos, estimulando uma cultura de desconstrução e construção contínua, de constante aprendizado e criação de valores sociais (CASTELLS, 2005).

0 estudo da chamada "terceira Itália" mostra que a formação de redes organizacionais foi positiva e incentivadora para o processo de reestruturação daquele País. Buscando saída para a crise que se instalava, sindicatos, governo e empresários decidiram cooperar para obter as reformas e buscar soluções para salvar a economia (FARAH 2002).

Diversos autores se dispuseram a estudar as redes de empresa e enumerar as suas principais vantagens (CASTELLS, 2005; PO RTER, 1999; ESSER et al., 1994; COUTINHO; FERRAZ, 1995; MACHAD 0, 2003).

A crescente relevância que 0 tema redes adquire, tanto na área acadêmica quanto na empresarial, motivou a realização deste estudo, com o intuito de compreender como a participação de uma empresa em deteminado Arranjo Produtivo Local pode interferir na sua competitividade, assim como identificar quais características os participantes deste APL reconhecem como importantes para o aumento da sua competitividade.

0 artigo está estruturado da seguinte forma: inicia-se com uma abordagem teórica sobre competitividade, tratando de alguns conceitos de autores renomados, com o intuito de entender 0 que vem a ser competitividade, passando para a apresentação de um modelo de competitividade sistêmica. Apósisto é definido o que é um APL e é apresentado um modelo de evolução dos APLs. Logo após, exibe-se uma síntese da metodologia utilizada na pesquisa, bem como é mostrado 0 Arranjo Produtivo Local deTurismo na Região das Lagoas. Por fim, são apresentados os resultados obtidos durante as pesquisas e as considerações sobre o estudo.

\section{FUNDAMENTAÇÃO TEÓRICA}

\subsection{Competitividade}

A constante busca para a compreensão dos fatores que contribuem e desenvolvem a capacidade competitivaé umapreo- cupação das nações, indústrias e organizações. 0 conceito de competitividade é amplamente discutido e diversas tentativas de estabelecer teorias e modelos capazes de explicar e avaliar as suas causas e efeitos são levados a efeito. Apesar de não haver uma definição específica e única para o que é competitividade, é fato a preocupação das empresas em lidar com a concorrência e competição cada vez mais crescentes (CO UTINHO ; FERRAZ, 1995; ESSER et al., 1994; PORTER, 1986, 1989, 1999).

As organizações buscam posição competitiva na indústria onde estão inseridas e, para isto, utilizam-se de estratégias que têm como objetivo principal o alcance e manutenção de vantagem competitiva. Indústria pode ser entendida como 0 grupo de empresas fabricantes de produtos que são substitutos bastante aproximados entre si (COUTINHO ; FERRAZ, 1995; PORTER, 1986; WIT; MEYER, 2004).

Porter (1999) destaca aimportância que as forças competitivas exercem sobre a empresa, pois a competição não se manifesta apenas na própria companhia ou na figura dos outros participantes, mas influencia-se da economia subjacente à empresa.

As forças competitivas evidenciadas porPorter (1999) são: Poder de negociação dosfomecedores; poder de negociação dos clientes; ameaça de novos entrantes no mercado; ameaça de produtos ou serviços substitutos; e manobras pelo posicionamento entre os atuais concorrentes do setor.

Cientes das forças que interferem no dia a dia da indústria, as empresas utilizam-se de estratégias na busca por uma vantagem competitiva sustentável. Estas estratégias podem ser explícitas ou implícitas, ou seja, elas "podem ter se desenvolvido explicitamente por meio de um processo de planejamento ou terem evoluído implicitamente através das atividades dos vários departamentos funcionais da empresa" (PO RTER, 1986, p. 13).

Ao analisar as vantagens competitivas de uma empresa, Porter introduz o conceito de cadeia de valor, que pode ser entendida como a representação das atividades executadas por uma organização para projetar, produzir, comercializar, entregar e sustentar seu produto. Em termos competitivos, valor é considerado o montante que os compradores estão dispostos a pagar por aquilo que uma empresa lhes oferece. 0 valor é reflexo do preço que uma empresa impõe sobre um produto e as unidades que ela pode vender. A cadeia de valores exibe 0 valor total da empresa e quanto maior este valor, maior a vantagem competitiva da empresa (PO RTE R, 1989).

As estratégias com que as empresas lidam com sua cadeia de valor, para atuar nas forças competitivas, criam vantagens competitivas em relação aos seus concorrentes. Pode-se entender que a competitividade de uma empresa está diretamente ligadaà vantagem competitiva que ela tem na indústria que está concorrendo.

Ferraz et al (1997, p. 3) definem competitividade como "a capacidade da empresa formular e implementar estratégias concorrenciais, que lhe permitam ampliar ou conservar, de forma duradoura, uma posição sustentável no mercado". Para Hamel e Prahalad (1995), a competição ocorre entre as empresas e grupos de empresas e não apenas entre ofertas de produtos ou serviços. 
Com base no preceito da relação da competitividade das empresas com 0 ambiente onde ela está inserida, será apresentado o modelo de competitividade sistêmica proposto por Esser et al (1994).

\subsection{M odelo de competitividade sistêmica deE sser et al}

No intuito de beneficiar a economia de mercado e a competitividade internacional desta economia, é necessário romper 0 modelo atual de relacionamento entre o Estado, o setor produtivo e a sociedade civil, visando a melhorar as bases jurídico-institucionais, socioculturais, infraestrutu-rais, assim como a política econômica processual. Alguns países em desenvolvimento, como a China e Coréia do Sul, têm a economia voltada com menor interferência do governo passa a ser substituído por outro padrão, onde as empresas desenvolvem relações interativas e cooperativas. Para tal, há um estreito diálogo entre os setores produtivo, científico, público e instituições intermediárias. 0 Estado assume a responsabilidade de criar, motivare coordenar ações com o intuito de criar uma estratégia competitiva durável (ESSE R et al., 1994).

É neste novo paradigma, onde o Estado desempenha importante papel no estímulo à competitividade das empresas, que surge o modelo de competitividade do GemanDedepment Institute(G D I). Este modelo, articulado em quatro níveis, utiliza o conceito de competitividade sistêmica e é apresentado conforme a figura 1:

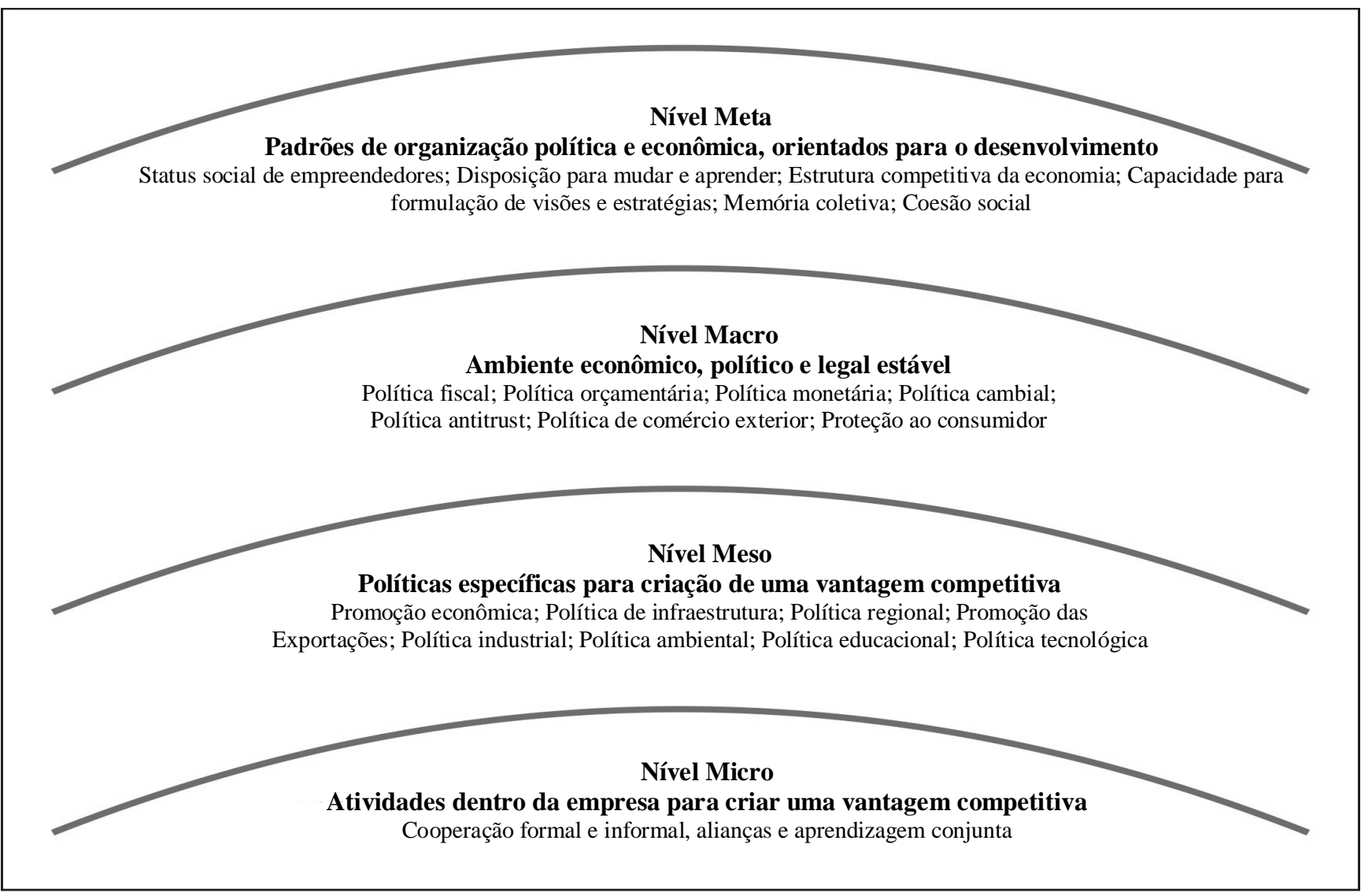

Figura 1: Níveis de competitividade Sistêmica

Fonte: Adaptado de Meyer-Stamer (2001).

tanto mercado interno, como ao mercado mundial. Também se caracterizam, no entanto, pela ênfase na integração nacional e social; na implementação de uma estratégia geral realista; na condução econômica criativa, inovadora e competitiva; na disposição de vincular os processos autônomos de aprendizagem com a aprendizagem de outros países exitosos, independentemente de seus regimes políticos (E SSER et al., 1994).

Aspolíticas econômicas têm relação estreita com a melhoria da competitividade do País. O crescimento econômico, entretanto, não é suficiente para aumentar, sozinho, a competitividade nacional. 0 conceito neoliberal que defende $o$ livre comércio
Neste modelo, a competitividade resulta da interação dos diversos agentes sociais participantes do processo. 0 diálogo entre os principais grupos de agentes sociais assegura a coordenação entre os quatro níveis sistêmicos.

O modelo proposto pelo GDI apresenta dois destaques principais. 0 primeiro decorre desta divisão em quatro níveis de análise (meta, macro, meso e micro).

0 nível meta propõe uma gestão que leva à solução conjunta de problemas, aos processos de aprendizagem e ao desenvolvimento da capacidade de previsão e resposta. No nível macro, é considerado o fato de que muitas fontes enseja insta- 
bilidade na macroeconomia. As mais importantes e influentes são os deficits do orçamento e da balança de pagamentos. No nível meso ocorre 0 entrosamento, com cooperação formal e informal entre empresas e o conjunto de instituições situadas junto aos dusters (núcleos industriais) nos quais operam. No nível micro, por fim, encontram-se as atividades das próprias empresas, direcionadas pelas características dos outros três níveis (MEYER-STAMER, 2001).

O segundo destaque está no seu direcionamento para a formação de redes sociais, principalmente nos níveis meta e meso.

\begin{abstract}
Em termos nacionais as políticas de nível meso apontam ao desenvolvimento de infraestruturas físicas especialmente concebidas para os clusters (p. ex.: transporte: portos, redes ferroviárias e estradas; telecomunicações; sistemas de abastecimento e tratamento: energia, água e esgoto, dejetos), e a desenvolver também estruturas intangíveis (p. ex.: desenvolvimento dos sistemas educacionais) (ESSER, et al., 1994, p. 34).
\end{abstract}

As políticas específicas para dusters além de melhorar 0 espaço mesonacional, também são importantes em termos regionais e locais. As políticas locais são essenciais para os núcleos industriais, pois a formação destes é mais dinâmica em espaços regionais delimitados. A proximidade geográfica dos envolvidos nos dusters constitui uma força produtiva substancial (ESSER etal.,1994).

\subsection{Arranjos Produtivos L ocais e a Competitividade}

O sucesso alcançado por diversas aglomerações tem provocado discussões quanto ao papel desempenhado pela concentração geográfica na competitividade das empresas. Segundo Marshall (1982), o fenômeno de concentração geográfica é tão antigo quanto o próprio comércio, entretanto recebe maior destaque com o passar dos anos. Esta crescente procura por agrupamentos despertou o interesse em utilizá-los nesta pesquisa.

O s agrupamentos aqui escolhidos foram os A rranjos Produtivos Locais, que podem ser definidos como uma concentração geográfica de empresas e instituições que se relacionam em um setor particular. Inclui, em geral, fornecedores especializados, universidades, associações de classe, instituições governamentais, bem como outras organizações que provêem educação, informação, conhecimento e/ ou apoio técnico e entretenimento (BNDES, 2008).

O estudo da chamada "terceira Itália" mostra que a formação deste tipo de rede organizacional foi positiva e incentivadora para a reestruturação daquele País. Buscando uma saída para a crise que se instalava, sindicatos, govemo e empresários decidiram cooperar para obter as reformas e buscar soluções para salvar a economia. 0 desenvolvimento italiano resultou de um compromisso das iniciativas empresariais locais em criar uma identidade regional nos âmbitos econômico, político e cultural, permitindo maior interação dos diversos agenteschave do processo (FARAH, 2002).

Spínola (1999) traz uma diferenciação clara de APL e duster. Para 0 autor, os arranjos locais tentam caracterizar os agentes não necessariamente empresariais. E les interagem de forma cooperativa. Tanto o duster como o APL dão importância à capacitação social, no contexto de educação da comunidade e cooperação com centros de ensino. No duster, há ênfase na aglomeração local de empresas em uma mesma atividade, enquanto no arranjo há um destaque para o papel desempenhado pelas instituições de coordenação.

As redes sociais contribuem com as empresas e produtores ao minimizar as dificuldades individuais e, ao mesmo tempo, maximizar os seus pontos positivos. A difusão da lógica de redes modifica a operação e os resultados dos processos produtivos, estimulando uma cultura de desconstrução e construção contínua, de constante aprendizado e criação valores sociais (CASTELLS, 2005). Para Porter (1999, p. 226), "Os aglomerados seriam definidos como um sistema de empresas e instituições inter-relacionadas, cujo valor como um todo é maior quea soma das partes".

Verschoore e Balestrin (2006) destacam cinco fatores competitivos das empresas em redes de cooperação: ganhos de escala e de poder de mercado (as empresas participantes da rede passam a ter maior poder de negociação com seus fornecedores); provisão de soluções (as empresas têm acesso a crédito, treinamento e outras ferramentas que não eram possíveis sem a formação da rede); aprendizagem e inovação (beneficiadas pela interação e práticas rotineiras de colaboração, desenvolvimento de competências e de habilidades coletivas, ou mesmo por meio de processos conjuntos de adaptação às exigências socioeconômicas); redução de custos e riscos (vantagem de dividir entre os associados os custos e os riscos de determinadas ações e investimentos que são comuns aos participantes); e relações sociais (o acúmulo de confiança e capital social por um determinado grupo de pessoas potencializa a capacidade individual e coletiva mediante práticas colaborativas).

Para contribuir com a análise dos fatores que interferem na competitividade dos participantes de Arranjos Produtivos Locais, será utilizado o modelo proposto por Machado (2003), que parte do princípio de que o APL passa por diversas etapas de evolução e que cada fase tem os seus padrões competitivos distintos. D urante este estudo, foi evidenciado o fato de que podem ser encontrados dois tipos básicos de vantagens: externas e internas.

No intuito de definir quais as vantagens externas e internas do APL, Machado (2003) observa o fenômeno da concentração geográfica das empresas e quais os fatores determinantes desta concentração. Estes fatores são divididos entre a economia extema e a economia interna, de acordo com os estudos realizados por Marshall (1982) e são apresentados na figura 2.

Para a criação do modelo de evolução dos APLs, foi considerada a hipótese básica de que a origem do APL está na adoção de inovações radicais no processo que, aliadas às condições locais, criam paradigmas de produção, com economias de escala superiores à existente. Inicialmente os APLs atendem a demandas de mercados próximose, em sau evolução, passam a atender mercados distantes (MACHAD 0, 2003).

A evolução dos APLsinicia-se na fase "Nascimento/ embrionário, onde há adoção de inovações com economias de escala significativas, associadas às condições locais que privilegiam a oferta de matéria-prima, insumos e mão-de-obra. A competi-

CONTEXTUS Revista Contemporânea de Economia e G estão. Vol.7 - № 2 - jul/ dez/ 2009. (21-28). 
ção é inicialmente por custos ea cooperação apresenta caráter informal. Na segunda fase, denominada "Crescimento", o APL passa a atrair setores montantes na forma de representantes. $O$ aumento da produção beneficia o ganho de escala. A demanda crescente de mão-de-obra induz à especialização. Inicia-se a preocupação com a qualidade e a cooperação evolui com aformação de instituições de apoio (MACHAD 0, 2003).

Nafase de maturidade, a estagnação dos mercados locais acirra a competição. A redução de margens obriga as empresas lideres a buscar novos mercados, o que culmina com a exportação. A diminuição da economia de escala evita a atração de novas empresas. A última fase, pós-maturidade ou rejuvenescimento, é marcada pela competição com outras localidades. Novos negócios com alto valor agregado são criados utilizando-se da competência acumulada pelo APL. Estes novos negócios podem dar novo impulso ao APL que se beneficia da reputação do aglomerado.
D entre as formas de pesquisas qualitativas disponíveis, optou-se pelo estudo de caso, pois esta modalidade se diferencia em virtude da delimitação precisa do objeto de pesquisa, 0 caso. Esta metodologia é também aconselhada quando o interesse do pesquisador envolve questões do tipo "como" e "por que". Vale ressaltar que o estudo de caso qualitativo não tem 0 intuito de realizar generalizações estatísticas, mas busca uma descrição densa e rica para constituir o real significado do evento em estudo (MERRIAM, 1998; PATTO N, 2002; YIN, 2001).

A seleção de amostrafoi intencional, definindo como caso de estudo o Arranjo Produtivo Local de Turismo Região das Lagoas pela facilidade de acesso aos entrevistados e por serum arranjo produtivo basicamente de serviços, o que difere dos comumente estudados APLs industriais. Para a seleção dos entrevistados, foi considerada a característica de destaque dos APLs para a interação com instituições de coordenação. A primeira entrevista foi intencional e realizada com a colaboradora

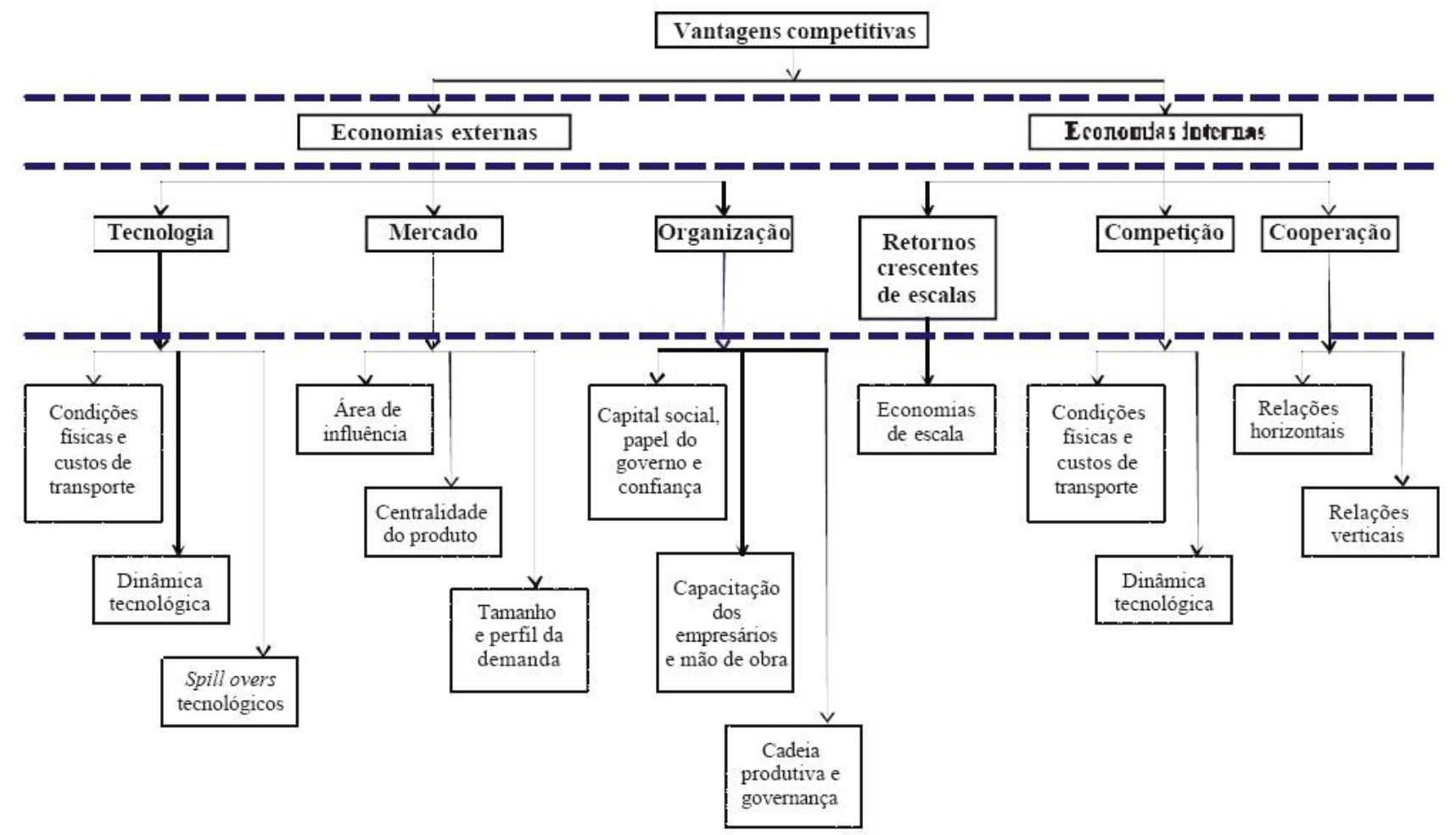

Figura 2: Fatores determinantes da concentraçäo geogratica de empresas

Fonte: Machado (2003, p. 11).

\section{METODOLOGIA}

Este estudo tem o objetivo de analisar quais características ou atividades, desenvolvidas pelo APL Turismo Região das Lagoas, em Alagoas, contribuíram positiva ou negativamente com a competitividade das empresas dele participantes. Para tanto utilizou-se de uma pesquisa qualitativa, pois este tipo de estudo é comumente empregado por pesquisadores que buscam compreender como os indivíduos entendem a realidade onde estão inseridos, afastando-se o mínimo possível da situação natural (MERRIAM, 1998). do SEBRAE e a Secretaria de Planejamento do Estado de Alagoas - SEPLAN/ AL, Gestora do APL em questão. Em seguida, adotou-se o uso da amostra por cadeia ou bola de neve, em que os próprios entrevistados sugerem outros sujeitos que possam contribuir com a pesquisa e compreensão do objetivo proposto (MERRIAM, 1998).

Para a coleta de dados form realizadas entrevistas, observação e análise documental, alcançando assim um universo de informações abrangente. A entrevista semi-estruturada permitiu certo grau de liberdade, sem que houvesse fuga do objetivo 
do trabalho. A observação e a análise documental contribuiram com os dados colhidos durantes a entrevistas, bem como possibilitaram a triangulação destes dados (MERRIAM, 1998).

$\mathrm{Na}$ pesquisa foram realizadas seis entrevistas, número considerado satisfatório, visto que foi alcançada a saturação dos dados (MERRIAM, 1998).

Segundo Merriam (1998), um estudo qualitativo básico busca compreender determinado fenômeno na visão de mundo dos respondentes e os resultados destes estudos englobam atividades de descrição e análise. Comumente estas análises envolvem a criação de categorias, que podem ser consideradascomo padrões repetidos de dados encontrados. Durante a análise dos dados e das entrevistas realizadas durante 0 estudo, foi observada a repetição de informações e estas foram agrupadas em diferentes categorias, facilitando o entendimento do fenômeno estudado (MERRIAM, 1998).

\section{ANÁLISE DOSRESULTADOS}

A qui serão apresentados os resultados obtidos durante a pesquisa. Como mencionado na introdução deste trabalho, 0 caso de estudo é o Arranjo Produtivo Local de Turismo na Região das Lagoas, que engloba seis municípios de Alagoas: Barrade São Miguel, Coqueiro Seco, Maceió, Marechal D eodoro, Pilare Santa Luzia do Norte.

Sua fase inicial de implantação se ocorreu em 2004, quando o SEBRAE - Serviço Brasileiro de A poio às Micro e Pequenas Empresas, e a Secretaria de Planejamento do Estado de Alagoas - SEPLAN/AL, iniciaram a fase do diagnóstico participativo. A fase de começo tinha o objetivo de traçar o perfil inicial do APL, com o nível de organização dos participantes, suas necessidades e anseios. A poiando-se no potencial turístico do Estado e no polo gastronômico que a região já possui, 0 APL de Turismo na Região das Lagoas foi formalizado com 0 objetivo de aumentar o número de turistas que circulam na região, bem como elevar sua taxa de permanência, impulsionando o comércio local.

Composto por donos de bares, restaurantes, hotéis e pousadas, rendeiras e barqueiros da região, o APL é coordenado pelo SEBRAE e pela SE PLAN/ AL e conta com a parceria de agentes financeiros, entidades de ensino e tecnologia, federações e entidades de classe, prefeituras municipais, fóruns e câmaras setoriais.

0 nome deste arranjo produtivo é uma referência às lagoas da região: Mundaú, Manguaba, Niquim e Roteiro. Os municípios que fazer parte do APL margeiam estas lagoas. D esde a sua criação, em 2004, diversas ações são desempenhadas com um destaque para o Festival Sabor das Lagoas, evento gastronômico, que em 2007 realizou a terceira edição.

A seguir serão apresentados os resultados, referentes à seguinte pergunta de pesquisa: Q uais os aspectos motivadores para 0 aumento da competitividade das empresas participantes de um Arranjo Produtivo Local de serviços? As respostas foram agrupadas em quatro categorias que surgiram de acordo com a repetição das informações prestadas pelos respondentes, bem como da análise documental.

\subsection{Aumento da divulgação da região}

A primeira categoriaidentificada durante a pesquisarelaciona-se à divulgação que a região recebe após a formalização do APL. D urante as entrevistas, todos os respondentes declararam que a região obtêm retorno positivo dos esforços para tomá-la mais conhecida.

Segundo Wilson Caliari, proprietário do restaurante Parada de Taipas, na praia do Francês, no Município de Marechal D eodoro, não havia um investimento em divulgação da região, em virtude do pequeno porte dos estabelecimentos que dela fazem parte. Para ele, o APL criou esta oportunidade.

D entre as ações responsáveis por esta divulgação, a colaboradora do SE BRAE-AL, gestora responsável pelo APL de Turismo na Região das Lagoas, Carolina Heemann, destaca: a participação em eventos específicos para a comercialização de roteiros turísticos, direcionados para operadores turísticos e jornalistas; a realização do Festival Sabor das Lagoas:

\begin{abstract}
Antes do início do Festival os jornais locais e regionais já produzem reportagens e este número de matérias cresce ainda mais na semana em que o evento tem início, com reportagens de capa e matérias televisivas. Esta mídia espontânea permanece durante todo o festival e já está presente na agenda cultural do Estado de Alagoas.
\end{abstract}

Alexandre Nigro, proprietário do Padrino Ristorante, também na praia do Francês, destaca que o Festival é muito bom para os restaurantes, mas que o movimento contribui com outros empresários da região: "As pessoas vêm de outros estados do País para participar do Festival e ficam hospedadas nas pousadas da região e também compram 0 artesanato daqui".

D ezenas de estabelecimentos participam do Festival e a culinária da região, em grande parte de frutos do mar, aliadas às belezas naturais do entorno, criam uma característica peculiar ao evento. Para Barney (2002), isto é considerado como um fator impulsionador da competitividade, visto que cria valor para o consumidor, é de imitação difícil e que somatório de características é escasso entre os competidores.

\subsection{Aumento da capacitação da mão-de-obra da região}

Q uando perguntados sobre quais as ações desenvolvidas após a formalização do APL que interferiram positivamente no dia a dia dos negócios, todos os entrevistados destacaram 0 acesso a cursos de capacitação.

Juliana Bevilaqua, da agência de turismo Sete Mares, enfatiza que, com o APL, a região das lagoas foi alvo de uma perceptível melhora na qualidade de atendimento aos clientes. Cursos de garçom, recepcionista, telefonista, camareiro(a), cozinheiro(a), gestão, dentre outros, foram realizados por instituições parceiras e ofertados para os participantes do APL. Juliana reforça a sua opinião sobre a capacitação:

\footnotetext{
Hoje eu me sinto bem mais tranqüila ao indicar um estabelecimento da região que sei que participa do APL, pois tenho convicção de que lá o turista receberá um atendimento de qualidade e que todos os quesitos de higiene e limpeza são observados
} CONTEXTUS Revista Contemporânea de Economia e G estão. Vol.7 - № 2 - jul/ dez/ 2009. (21-28). 
Adriana Franco, proprietária da pousadaCapitães de Areia, na praia do Francês, admite que, quando foi implantar o seu empreendimento, sentiu dificuldade em contratar os moradores da região para algumas funções específicas, mas que os cursos realizados contribuíram positivamente com o seu negócio.

Verschoore e Balestrin (2006) incluem o treinamento em um dos cinco fatores competitivos das empresas em redes de cooperação. Para os autores, a provisão de soluções é um destes cinco fatores, pois os participantes têm acesso facilitado a ferramentas que contribuem para a competitividade do estabelecimento. Os cursos oferecidos para os que fazem parte do APL é uma destas soluções.

\subsection{A Cooperação entre os participantes}

A cooperação das empresas é um dos principais destaques que os autores fazem ao estudar as formações de redes empresariais (CO UTINHO; FERRAZ, 1994; MACHAD 0, 2003; PO RTER, 1999; CASTELLS, 2005). A pesar desta característica de destaque entre os autores, a cooperação não foi citada por alguns dos entrevistados.

Adriana Franco, proprietária da pousadaCapitães de Areia, cita que, entre os proprietários de hotéis e pousadas da região, 0 espírito de cooperação começa a substituir a competição, poisjá existe a indicação de hóspedes entre eles. Isto acontece quando um estabelecimento está com seus quartos ocupados, ou até mesmo quando o cliente, ao procurar informações sobre a empresa, admite que este não era o perfil que estava procurando.

Juliana Bevilaqua, da agência de turismo Sete Mares, acentua que a cooperação entre as pousadas contribui com seu trabalho:

Diversas agências de turismo preferem não trabalhar com regiões como a das Lagoas, pois elas dificilmente têm hotéis de grande porte. Isto se deve ao número de quartos disponíveis para receber um grande grupo. De alguns meses para cá, nós temos observado que isto nem sempre é um empecilho para levarmos um grande grupo para a Região das Lagoas, pois as próprias pousadas se organizam para acomodar todos os hóspedes de um grande grupo, trocando informações entre elas.

\subsection{A troca de experiências entre os participantes}

A última categoria identificada com base nas entrevistas coletadas é destacada por Verschoore e Balestrin (2006), quando abordam a aprendizagem e ainovação como fatores que interferem na competitividade das empresas em redes de cooperação. Segundo os autores, as empresas são beneficiadas pela interação delas, com a criação de práticas rotineiras de colaboração.

Wilson Caliari, proprietário do restaurante Parada de Taipas, ressalta que já observa entre os proprietários a troca de informações sobre as melhores práticas. Para ele, as reuniões promovidas entre os participantes do APL são úteis para a tomada de decisões, bem como para manter o contato entre eles, propiciando a chance de trocar experiências.

A proprietária do restaurante Píer Pontal, localizado no bairro do Pontal da Barra, em Maceió, Dagmar Canesi, também destaca a importância da troca de experiências:
As reuniões promovidas pelo APL têm sido úteis de diversas maneiras. Nós conseguimos trocar idéias, planejar as ações e observar como outros empresários estão buscando superar suas dificuldades. Mas também têm sido interessante porque nós podemos tomar conhecimento de como outras pessoas estão lidando com algo. Muitas vezes, nós aqui do Pontal, ficamos sabendo como os proprietários de estabelecimentos da Massagueira (em Marechal D eodoro) estão lidando com algo e vice-versa.

\section{CON SIDERAÇÕESFINAIS}

Ao iniciar a análise do APL de Turismo na Região das Lagoas, identifica-se o fato de este se encontrar na fase de nascimento/ embrionário, passando para a fase de crescimento, segundo modelo sugerido por Machado (2003). Esta constatação pode ser confirmada, pois o APL ainda apresenta uma cooperação de caráter mais informal, com a competição baseada inicialmente por custo, o que caracteriza a primeira fase. Por outro lado, o Arranjo já começa a apresentar características de crescimento, como a demanda crescente por mão-de-obra, incentivando a especialização, o aumento da preocupação com a qualidade e a atração de participantes para o APL.

Sua característica de arranjo produtivo em fase de nascimento/ embrionário justifica que as ações destacadas pelos entrevistados estejam basicamente concentradas nos níveis meta $\mathrm{e}$ micro, segundo modelo proposto por Esser et al. (1994), sendo o segundo nível o mais perceptível. 0 nível micro engloba as atividades internas da empresa, onde há uma cooperação formal e informal entre os participantes e a constituição de alianças e a aprendizagem conjunta.

D entre as categorias encontradas durante a pesquisa, 0 "Aumento da divulgação da região" foi a que causou maior surpresa, visto que isto não é referenciado na literatura sobre redes. Esta característica pode ser atribuída à natureza do arranjo produtivo. Por ser um APL de serviço, focado no desenvolvimento do turismo, o seu intuito não é o de promover produtos específicos, mas o de trabalhar a junção de todos eles. 0 somatório dos serviços oferecidos pelas empresas da região forma um destino tuństico e este destino é passível de propagação única, o que dificilmente ocorre em outros tipos de APL.

As outras três categorias são referenciadas por estudiosos de redes empresariais, entretanto o destaque nem sempre é para 0 aumento da capacitação da mão-de-obra, mas para a cooperação em si e a troca de experiências, categorias menos citadas durante as entrevistas.

A intenção de um estudo de caso não é a generalização (ME RRIAM, 1998), mas esta pesquisa pôde comprovar, por meio das entrevistas, que a participação no APL de Turismo Região das Lagoas proporcionou a oportunidade de incentivo às vantagens competitivas dos participantes e há um consenso entre eles em relação ao benefício em fazer parte destaformação. Wilson Caliari contribui para esta afirmação, declarando: "Para o nosso restaurante existe o antes e o depois do APL".

D urante a coleta de dados, sentiu-se dificuldade de realizar as entrevistas com os proprietários de estabelecimentos que já residiam no local há diversos anos. G rande parte destes 
moradores fazia ou faz parte de vilas de pescadores, que garantiam a sua sobrevivência por meio da pesca artesanal e passaram a trabalhar em outros ramos, principalmente, em virtude da poluição das lagoas. Sugerem-se aqui a pesquisa da influência da cultura local no perfil empreendedor dos participantes do APL, como também a interferência da formação acadêmica na motivação e participação efetiva das ações desenvolvidas pelo APL.

\section{REFERÊNCIAS}

BARNEY, Jay. Gainingand sustaining competitiveadtantage New Jersey: Prentice Hall, 2002

BND ES. Anranjos Produtivos Locais e Desenduimento Disponível em: <http:/ / www.bndes.gov.br/ conhecimento/ seminario/ apl.pdf> Acesso em 13 de fevereiro de 2008

CASTELLS, Manuel. A Sociedade em Rede São Paulo: Paz e Terra, 2005

COUTINHO, Luciano; FERRAZ, João Carlos. Estudo da competitividade da indústria brasileira. 3 ed. Campinas: Papirus/ Unicamp, 1995.

ESSER, Klaus; HILLEBRAND, Wolfgang; MESSNER, Dirk; MEYER-STAMER, Jörg. Competitividad sistémica: competitividad internacional de las empresas y políticas requeridas. Instituto Alemán de D esarrollo, Berlin, 1994.

FARAH, M. Uma Proposta de Estruturação da Capacidade Compditiva das Pequenas e Médias Empresas Metal-Mecânicas da Regãa de Cunitiba Através da Fomação de umCluster. Tese (D outorado em Engenharia de Produção pela Universidade Federal de Santa Catarina), Florianópolis, 2002.

FERRAZ, J. C.; KUPFER, D.; HAG UENAUER, L. Madein Brazil - desafios competitivos para a Indústria. Rio de Janeiro: Campus, 1997.

HAMEL, Gary; PRAHALAD, C. K.. Competindo pdo futura estratégias inovadoraspara obter o controle do seu setor e criar os mercados de amanhã. Rio de Janeiro:Campus, 1995.

MACHAD 0, S. A, Dinâmica dos anranjos produtivos locais: um estudo de caso em Santa Gertrudes, a nova capital da cerâmica no Brasil. São Paulo: USP- Escola Politécnica. Tese (D outorado). 2003.

MARSHALL, A. Prinápios de Econama. São Paulo: Abril cultural, 1982.

MERRIAM, S. Qualitative Research and Case Study Applications in Education SanFrancisco: Jossey-Bass, 1998.

MEYER-STAMER, Jörg. Estratégias de desenndvimento local e regjonal: dusters, política de localização e competitividade sistêmica. ILDES - Fundação Friedrich Ebert, São Paulo, 2001. D isponível em http:/ / www.fes.org.br. Acesso em 17 de outubro de 2007

NORONHA, E. e TURCHI, L. Política Industrial e Ambiente Institurional na Análise de Ananjos Produtivos Locais Pesquisa Arranjos Produtivos Locais (APLs): a construção da cooperação - IPEA. Brasília, 2005.

PATTON, M. Qualitativereanchandevaluationmothods 3. ed. Thousand O aks:Sage, 2002.

PORTER, Michael E. Estratéga Competitiva: Técnicas para análise de indústrias e da concorrência. Rio de Janeiro: Elsevier, 1986

. Vantagem Competitiva: Criando e sustentando um desempenho superior. Rio de Janeiro: Elsevier, 1989

de Janeiro: Elsevier, 1999
SPÍNO LA, Vera. Conceito de Arranjo Produtivo: Clusters x Arranjos Produtivos Locais, Conjuntura \& Plangamento SEI - Bahia, n. 65 cap. 1, 19-23, 1999.

VERSCHO ORE, Jorge; BALESTRIN, Alsones. Fatores Competitivos das Empresas em Redes de Cooperação. In: ENCONTRO NACIO NAL DA ASSO CIAÇÃO NACIONAL D OSPRO G RAMAS DE PÓ S-GRADUAÇÃO EM AD MONISTRAÇÃO, 30, Salvador, 2006. Anais.. ANPAD, Salvador, 2006.

WIT, B. de e MEYER, R. Strategy: process, content, context an international perspective. 3 ed. London: Thomson, 2004.

YIN, R. K. Estudo de Caso planejamento e métodos. 2. ed. Porto Alegre: Brookman, 2001. 